\title{
PROCESSOS D'INTERLITERARIETAT A CATALUNYA. EL COMPARATISME DE DIONÝZ ĎURIŠIN COM A PROPOSTA PER A LA LITERATURA CATALANA
}

\author{
ANTONI MARTÍ MONTERDE
}

\begin{abstract}
This essay aims to propose a revision of Dionýz Ďurišin's concept of Interliterary Community and Pierre Bourdieu's concept of Field, in order to explain the possibilities of an inner comparative frame in Catalonia, which may be very interesting to the contemporary idea of European literature. The frame reflection by Durišin, subject to a thorough review, may be a good framework to understand the place of Catalan literary tradition in European literature in the twentieth century, and even more clearly in the last thirty years. But in this revision it's necessary to consider that interliterariness is deeply conditioned by tension between political, intellectual and literary fields. Catalonia can be conceived as a community with a double interliterary process: on the one hand, by belonging to the Iberian interliterary community - which differs from others by its definition of conflict-, but on the other hand in an inner relationship with literatures written in Spanish in Catalonia - by Catalans but also American writers-, with the growing situation of literatures written in others languages in Catalonia, with other individual writers' situations, and so on; all this together with current relations with European and American literature. So Catalonia should be a double case because the relationship between Catalan literature and other literatures occurs both outside and inside, in a dimension almost unique in Europe, but not quite unlike other European references. In this respect, Catalan literature may become, along with these other references, a key part of the redefinition of contemporary cultural identity.
\end{abstract}

\section{L}

literatura - la cultura en general - ja no ocupa el lloc central que en altres temps va tenir en la constitució de les societats, però paradoxalment això no impedeix que, a Catalunya, el camp literari sigui escenari i objecte alhora d'algunes de les més enceses polèmiques polítiques dels darrers anys. ${ }^{1}$ Ara bé: el cas català no representa cap excepció a Europa, i per tant el seu estudi s'hauria d'alliberar dels dramatismes amb què sovint se'n parla, però també cal fer una passa endavant per situar-lo en aquest context europeu de reflexió que el fa intellligible. Precisament per això cal pensar en la manera com s'establirien les relacions entre la literatura catalana i les literatures del seu entorn - espanyol, ibèric, europeu; i en un altre pla, occidental, mundial - arribat el moment de la independència política efectiva: perquè l'endemà de la constitució de Catalunya com a Estat independent en el si de la Unió Europea, en aquest país hauran canviat moltes coses, però d'altres no: continuaran parlant-se les mateixes llengües i continuarà escrivint-se la mateixa literatura, o literatures. I això serà important tant en el terreny exterior com en l'interior, en el camp literari nacional i en el camp literari internacional. 
El concepte de camp - literari, polític, del poder, acadèmic...- definit per Pierre Bourdieu resulta, en aquest sentit, una primera referència força pertinent. El sociòleg francès parlava d'un "champ de forces agissant sur tous ceux qui y entrent, et de manière différentielle selon la position qu'ils y occupent ... en même temps qu'un champ de luttes de concurrence qui tendent à conserver ou à transformer ce champ de forces ... Le champ de forces est ausi un champ de luttes pour transformer le rapport de forces" (Bourdieu, "Le champ littéraire” 4-5, I9). Aquesta definició de camp implica també una perspectiva marcada per l'espai de possibilitats, i no sols circumscrit a l'anàlisi dels fets donats. D'altra banda, en el cas que ens ocupa, caldria assenyalar que la noció de camp resulta interessant també pel seu qüestionament de la transparència de l'internacionalisme literari, intellectual, filosòfic, acadèmic o editorial. Una veritable inquietud per afavorir la internacionalització de la vida intellectual passa per tenir present que:

On croit souvent que la vie intellectuelle est espontanément internationale. Rien n'est plus faux. La vie intellectuelle est le lieu, comme touts les autres espaces sociaux, de nationalismes et d'impérialismes, et les intellectuels véhiculent, presque autant que les autres, des préjugés des stéréotypes, des idées reçues, des représentations très sommaires, très élémentaires, qui se nourrissent des accidents de la vie quotidienne, des incompréhensions, des malentendus, des blessures. (Bourdieu, "Les conditions sociales" 3)

No és una altra la situació en què es troba el camp intellectual català en la seva relació amb l'altre camp intellectual amb què estableix les seves principals relacions internacionals en l'actualitat, l'espanyol; amb l'afegit que aquesta mateixa internacionalitat al si de l'Estat és, de fet, una part important de la qüestió, ja que condiciona constantment la resta de la seva internacionalitat. Tot plegat exigirà un esforç en què la literatura comparada pot jugar un paper decisiu de clarificació metodològica, gràcies a la referència a d'altres situacions semblants.

Un eix teòric i metodològic fonamental que podria contribuir de manera notable a aquesta possible clarificació parteix d'una aportació feta des d'un altre context molt concret, l'anomenada Escola de Bratislava, encapçalada per Dionýz Durišin, que va proposar, en el darrer terç del segle xx, una nova categoria per organitzar les relacions entre literatures. Aquesta categoria és la de comunitats interliteràries, que serien les unitats resultants del que el comparatista eslovac anomena processos d'interliterarietat, que conduirien a una nova concepció de la literatura mundial. El plantejament inicial seria el següent:

Les relations nationaux littéraires expriment le caractère systematique et intégrale de la littérature nationale en tant que d'un ensemble et d'une unité historique organique. Les rélations interlittéraires mettent en corrélation cet ensemble avec les ensembles plus grands, avec les unités histórico-littéraires supérieures en un certain sens, et en plus, plus larges. Les rélations nationaux littéraires sont les rélations entre les phénomènes dans le cadre d'une seule littérature nationale. Les rélations interlittéraires expriment les liens en dehors d'une seule littérature, derrière ses frontieres. Entre les pôles extrêmes mentionnés, 
la littérature nationale et la littérature mondiale, il existe une unité contradictoire et dialectique qui se traduit dans la pratique historico-littéraire comme une tension créatrice entre l'histoire des littératures nationales et de la littérature mondiale, ou bien entre les processus national littéraire et interlittéraire. (Communautés interlittéraires 22)

Malgrat el seu esquematisme inicial, aquest plantejament pot donar molt bons resultats a partir de situacions com la catalana, i de fet ja s'està sotmetent a una profunda revisió i desenvolupament des de diferents contextos (Cabo, Domínguez, Casas, Martí). ${ }^{2}$ Resulta especialment interessant per la idea d'unitat contradictòria i dialèctica que genera una tensió creadora, i pel fet de considerar-ho tot plegat com un procés, que seria nacional i interliterari - i no merament literari internacional-. Els processos interliteraris exigirien la consideració de grans unitats relacionals que serien les veritablement rellevants en el desenvolupament de la literatura i les més interessants per al comparatisme. Aquestes unitats serien les comunitats interliteràries (tipus estàndard), recognoscibles a partir d'una certa cohesió geopolítica, geohistòrica i geoliterària d'un conjunt de literatures nacionals que no poden ser considerades de manera isolada. Les comunitats interliteràries es definirien fonamentalment per factors geogràfics, ètnics, lingüístics, politicoadministratius, ideològics i confessionals; a aquests factors, s'hi poden afegir condicionants colonials, religiosos o d'altres factors diferencials de les unitats literàries singulars, que marcarien la distinta evolució dels conjunts supranacionals, fins i tot determinant tipologies diverses. Cal subratllar que, per a Durišin, els factors ètnics i lingüístics, que en altres concepcions de les relacions entre literatures ocuparien el centre de la reflexió, no són tan decisius per a la constitució de les comunitats interliteràries com els geogràfics, els sociopolítics i els administratius (Communautés interlittéraires 3 I-36). Així, les literatures eslaves, germàniques i romàniques s'ordenarien seguint un principi ètnic; les literatures de l'Europa central, oriental i occidental, segons un principi geogràfic, $\mathrm{i}$ les literatures del bloc soviètic, com un tipus particular, d'acord amb un principi ideològic (Theory of Interliterary Process I 25-I 27). Com es pot apreciar, la tria del terme comunitat no és neutra, i Durišin mateix n'assenyala la rellevància:

Communauté interlittéraire ... n'attribue aucune valeur exclusive au facteur géographique, mais s'ouvre à la différentiation plus detaillée: aspects géographique, institutionnel et politique, idéologique, ethnique, la langue, etc. La notion même de communauté suggère une certaine forme d'interférence intérieure, de cohésion et de l'unité. Le cadre de la communauté concrète facilite des analyses ultérieures des littératures nationales qui en font partie, se prênant de même à l'analyse des caractères et des facteurs actifs dans le processus d'unification. (Aspects ontologiques I7)

Per a Ďurišin, en el pla de la realitat quotidiana de la creació de les obres i les interrelacions entre escriptors, l'organització estatal, la concreció sociopolítica de les ideologies i la cohesió geogràfica determinada en gran part per aquests dos factors fins i tot arribaria a determinar la manera d'establir relacions 
per sobre de les definicions ètniques o lingüístiques de la literatura. Però se li pot retreure que atorga a la noció de comunitat una dimensió unificadora en un procés que hauria de portar a la categoria final de la literatura mundial. Allò ben cert és que l'existència d'una comunitat interliterària no implica, necessàriament, un procés d'unificació. Val a dir que una apreciació com aquesta no s'entén sense recordar la ubicació en l'Europa del bloc comunista de l'Escola de Bratislava, com ho prova el cas de la unitat i comunitat de la literatura socialista - per sobre de les tensions nacionals, com per exemple la que es dóna entre magiars i eslovacs (Durišin, Theory of literary comparatistics 283)-. Menys rígida resulta la formulació que li va donar posteriorment Marián Gálik, per a qui "interliterariness ... leaves aside the purely ethnic or national aspects of literatures (or the aspects that define their individualities or individual qualities) and focuses on the trans-ethnic, transnational, and lately on the geoliterary development as a whole", de manera que les comunitats interliteràries serien "supranational and supraethnic conglomerates of literatures coming into existence, changing and disappearing in historical developments conditioned spatially and temporally by ethnic, linguistic, national, and even ideological factors" (Gálik, "Comparative literature" 97-I00). Ara bé: com ha recordat una altra integrant de l'Escola de Bratislava, Libusa Vajdová ("Les modes d'organisation" I9-27), les literatures nacionals constitueixen un factor integrador decisiu en aquest procés, en tant que l'Europa actual no s'entén sense la idea de nacionalitat. Precisament els processos interliteraris mostrarien encara amb més evidència la inestabilitat de la mateixa idea de nació, i per tant, també seria inestable la definició de comunitat interliterària. Això quedaria també clarament exposat en la idea de binacionalitat o biliterarietat que mostren ben sovint els autors en determinades comunitats interliteràries i fins i tot fora del seu marc.

La literatura catalana formaria part del que Durišin anomena una comunitat interliterària específica. Una comunitat interliterària específica es definiria igual que una comunitat interliterària, però tindria formes de coexistència caracteritzades per una interacció que evolucionaria de manera més intensa i directa. Durišin posa com a exemple de comunitat interliterària específica els casos de les comunitats de les literatures txeca i eslovaca, de les literatures balcàniques dins el marc de l'antiga Iugoslàvia, de les literatures russa, ucraïnesa i bielorussa en l'antiga URSS i de les literatures espanyola, catalana, basca i gallega a Espanya (Ďurišin, Communautés interlittéraires 22-23) —aquesta darrera, després desenvolupada com a comunitat interliterària específica ibèrica-. Aquestes són les que va definir en un primer moment Ďurišin, però caldria afegir, si més no, casos com el de Suïssa, Bèlgica o Escandinàvia, que Durišin pràcticament no caracteritza; i també caldria definir què fer amb llengües literàries concretades en diverses tradicions literàries nacionals —el castellà, l'anglès, recança expressada per Susan Bassnett (48), fonamentalment - i repensar aquestes categories a partir de casos com el de Trieste, el de Galícia o precisament el de Catalunya. Una comunitat interliterària és, doncs, un conjunt de literatures nacionals que mantenen uns lligams entre si diferents dels que mantenen, per separat, cadascuna 
d'aquestes literatures nacionals amb la resta de literatures del seu entorn (que no formen part de la mateixa comunitat interliterària) i, en darrera instància, amb el conjunt de la literatura mundial, la qual cosa determina també possibles processos interliteraris entre diferents comunitats interliteràries. Aquesta qüestió és especialment important pel que fa al que Durišin anomena centrisme (Ďurišin, Communautés interlittéraires 24), que també pot considerar-se una xarxa interliterària (Durišin i Gnisci, Il Mediterraneo), un gran marc de referència de diverses comunitats interliteràries, específiques o estàndard. La comunitat interliterària específica ibèrica estaria fortament vinculada al centrisme mediterrani (els altres dos són el centreeuropeu i el septentrional). Aquesta ubicació en el centrisme mediterrani es pot considerar especialment desenvolupada a través del Noucentisme, tant en termes estètics com polítics; però cal tenir present que, en tant que reacció clàssica, el Noucentisme no s'entén tampoc sense una referència francesa: Charles Maurras, i com a reacció al nordisme del Modernisme. Dit d'una altra manera: March no es relaciona amb la cultura mediterrània de la mateixa manera que Eugeni d'Ors o Carles Riba; pel que fa al segle $\mathrm{xx}$, resulta evident que la pertinença al centrisme mediterrani resulta matisada per les relacions amb el centrisme centreeuropeu. D'altra banda, pel que fa a les paradoxes de la proposta sobre centrismes, no cal dir que l'adscripció de les literatures galaicoportuguesa i basca al centrisme mediterrani resulta força complicada; però des del punt de vista d'algunes propostes iberistes sorgides a Catalunya (Martínez Gil), si més no la primera pot resultar coherent.

Considerem que aquest pot ser un bon punt de partida per estudiar la posició de la literatura catalana en els múltiples contextos en què s'inscriu: autonòmic, estatal, nacional, euroregional i europeu occidental. Les relacions de la literatura catalana amb la resta de les literatures europees es donen dins un marc estatal problemàtic, de vegades mirant de prescindir-ne, però en la major part de les ocasions condicionades per aquest marc, que no es limita a una contingència administrativa des del moment que la mateixa possibilitat de canviar aquesta contingència modifica políticament les condicions en què es concreta. En termes individuals, creadors, aquest marc pot ser si fa no fa obviat o eclipsat per prioritats estrictament literàries; però és gairebé ineludible en termes collectius i, sobretot, institucionals. La literatura portuguesa no té aquests conflictes - encara que la posició de Saramago, o la de Vargas Llosa pel que fa al cas americà, siguin percebudes de manera ambigua-. En aquest sentit, l'iberisme no és una proposta internacional, sinó una resposta a una situació nacional catalanoespanyola: l'iberisme, com el federalisme, és una de les opcions que ha hagut de prendre el catalanisme al llarg dels anys en el debat amb Espanya. La tendència seria, doncs, a reduir la comunitat interliterària ibèrica als marges estatals espanyols, amb projeccions simbòliques, més que efectives, al camp portuguès - $\mathrm{i}$, només de vegades, iberoamericà, però obviant que, dins la península Ibèrica, és el camp editorial barceloní dels anys seixanta i setanta el que determina tota una rearticulació de la literatura llatinoamericana-. Una rearticulació que, en canvi, semblaria sustentar només una mena de simbòlica uni- 
versalitat de la llengua literària espanyola, reiteradament impugnada i refutada des d'Amèrica, que ja només té alguna eficàcia performativa de portes endins d'Espanya.

A més a més, cal recordar que Ďurišin planteja tres possibilitats importants, de les quals Catalunya és un exemple clar: que el conflicte sigui determinant en les relacions interliteràries; que una literatura pugui passar d'una comunitat interliterària a una altra, $\mathrm{i}$ també que les comunitats interliteràries poden desaparèixer, la qual cosa no les condemna a deixar de ser un objecte de la història literària. Potser ara com ara la més important és la consideració que dins les comunitats interliteràries les relacions poden establir-se també a través del conflicte: que les comunitats interliteràries en conflicte siguin un tipus especial de comunitat interliterària específica, definit per la insuficiència — per fracàs o per inviabilitat - de la cohesió politicoadministrativa, les tensions identitàries i la diferent situació en relació amb el temps històric de cadascuna de les entitats que la integren. És evident que el conflicte entre projectes nacionals és un tret distintiu de les relacions entre les cultures ibèriques. D'altra banda, la diferent articulació interliterària dels camps intellectual i literari a Catalunya demostra que la literatura catalana s'ha trobat molt més nítidament inscrita en una comunitat interliterària organitzada al voltant de França que no pas al voltant de la literatura espanyola; però, si s'hagués concretat de manera absoluta aquesta adscripció, el conflicte no hauria estat menor. Amb tot, aquesta possibilitat pertany a un cicle que s'assembla més al dels temps de Baroja que als nostres: en aquells anys, per reprendre la fórmula d'Ortega, si Espanya era un problema, Europa era la solució; en els nostres temps, des de la perspectiva de la literatura catalana, el problema és que Europa no existeix prou com a realitat en la qual fer fonedissos o, si més no, replantejar certs debats d'una estretesa singular. La dimensió estatal espanyola d'una part important d'aquesta comunitat interliterària específica resulta molt clara, i planteja asimetries determinants: és el que Durišin anomena "condicionament històric de la interliterarietat i de les comunitats interliteràries", que, en alguns moments, sembla abocat a presentarse en forma de sobredeterminació administrativa de la forma Estat, de la política i la ideologia com a marc de caràcter programat en el qual es desenvolupen els "sistemes literaris multinacionals". Els exemples que proposa Durišin: l'exIugoslàvia, l'ex-Unió Soviètica, l'ex-Txcoslovàquia, poden considerar-se la prova de la seva inestabilitat, i està del tot per demostrar la seva afirmació sobre el cas de l'Estat espanyol: "Sur d'autres principes ést fondée l'únité du système littéraire multinational de l'Espagne qui unit dans une communauté interliteràire multinationale les littératures castillane, catalane, galicienne et basque" (Durišin, Communautés interlittéraires 35). Això pot ser així, afortunadament, en l'actualitat; així ho podia ser en el segle Xvir; o en el xv, sense que les situacions de cada moment puguin ser considerades ni tan sols equivalents. Però no era així durant el segle XviII, i menys encara durant el franquisme: és dir, durant quaranta anys del segle xx que, afegits a la dictadura de Primo de Rivera, sumen gairebé mig segle d'administració totalitària dels béns simbòlics i no simbòlics, 
precisament en el moment històric europeu en què el concepte de comunitat interliterària sorgeix i sembla més adient. Els factors coercitius com a element de cohesió politicoadministrativa amb objectius polítics més que literaris han estat massa presents en la realitat de la comunitat interliterària ibèrica per a pensar que no han deixat una empremta que encara cal comprendre plenament.

A Catalunya, a diferència d'altres comunitats interliteràries específiques, la superposició geogràfica de tradicions literàries en llengües diferents és un fet, $\mathrm{i}$ per tant ha de marcar els processos interliteraris de manera ineludible, i no sempre a través d'anècdotes terribles, sinó també de categories plenes de sentit constructiu per elles mateixes. Per això, entre d'altres raons no menors, també caldria definir una altra categoria derivada de la de comunitat interliterària de Durišin, que Catalunya permet albirar clarament: el que podríem anomenar una comunitat interliterària doble. En un territori com el català, la literatura en llengua catalana mantindrà - precisament en els termes en què es defineix una comunitat interliterària - unes relacions amb la literatura en castellà que ja no podran plantejar-se en termes de supranacionalitat, sinó de constitució d'un únic espai públic en el qual el sistema literari en català i en castellà —bé amb un camp literari doble o bé amb dos camps literaris diferenciables però inseparables- desenvoluparà unes noves relacions específiques entre ells. I, de manera conjunta o no, tots dos establiran relacions amb la resta de les literatures que partiran necessàriament de situacions i processos interliteraris anteriors, relacions que tindran una gran transcendència també en el camp intelllectual.

Cal preguntar-se com es dóna la relació, des de qualsevol de les posicions en els respectius camps literaris, amb la resta de literatures, especialment les europees. En un context tan complex, aquesta relació ha de ser força diferent de com es produeix en contextos homogenis i monolingües. A través de les traduccions enteses com a part fonamental d'un camp literari com el català, la tradició literària catalana ha anat constituint-se; el fet que els escriptors catalans - en una llengua o en l'altra - tinguin accés a traduccions en totes dues llengües ha d'implicar una manera d'articular aquestes lectures i de desprendre'n una reformulada internacionalitat literària. Però, a diferència de la riquesa de plantejaments d'altres èpoques, el context actual es caracteritza per l'homogeneïtat de les decisions editorials respecte a la política de traduccions, que gestiona les versions catalana i castellana en un sol paquet de negociacions, sense pensar en les respectives tradicions. Que un escriptor català en castellà sigui lector de Marcel Proust i Lampedusa tindrà uns efectes en totes aquestes qüestions si aquest escriptor és, a més a més, lector de Llorenç Villalonga i Miquel Pairolí. Que un escriptor català en català sigui lector de Baroja, Balzac o Colette tindrà uns efectes en totes aquestes qüestions si aquest escriptor és, a més a més, lector de Juan Marsé. Que dos dels grans llibres de poesia catalana del segle xx siguin dos textos d'exili: les Elegies de Bierville de Carles Riba i el Nabí de Josep Carner, hauria de tenir-se sempre present, abans de començar a parlar d'aquestes qüestions; que en els informes de lectura de la censura relatius a Últimas tardes con Teresa, de Marsé, es llegeixi l'afirmació següent, firmada per 
Carlos Robles Piquer en carta al ministre Manuel Fraga Iribarne: "Una de las razones por las que creo que la novela debería autorizarse es la de que está escrita en castellano, cosa que me parece importante cuando tantos catalanes se inclinan hacia su lengua vernácula" (Rodríguez Fischer I 2 I), hauria de recordar-se com a norma d'època. El camp literari s'articula sobretot en present, però no s'explica sense el passat, especialment el passat immediat, però que sembla remotament oblidat.

Tot plegat determina unes relacions intrínsecament difícils, però que marquen diferències sensibles amb el que s'esdevé en el camp literari espanyol. Aquest també és un factor d'independència. D'altra banda, ha de ser considerada també una noció especialment interessant i que, en el cas de les comunitats interliteràries específiques, resulta molt habitual: els fenòmens de biliterarietat o pluriliterarietat, i binacionalitat o plurinacionalitat, d'evident vinculació al bilingüisme; aquestes nocions s'aplicarien a escriptors i obres, però també als lectors i els crítics que pertanyen a dos o més sistemes literaris al llarg de la seva trajectòria literària, sota alguna forma de migració o de coexistencia. Aquesta condició, inestable en la vida d'un individu, que pot ser intencionada, apresa, natural o contingent, simètrica o asimètrica, entre moltes altres possibilitats, pot ser motivada per qualsevol aspecte dels múltiples factors constitutius de les comunitats interliteràries, i determina per a l'individu i la seva obra una posició interseccional i una diversitat de funcions en cada situació; per tant, aquestes figures, especialment pel que fa als escriptors, són d'una gran transcendència per a la constitució de la comunitat interliterària (Durišin, Communautés interlittéraires $5 \mathrm{I}-53$ ) i ho serien especialment en una comunitat interliterària doble, però constituiria un error d'enfocament definir-la només en funció d'aquestes figures, o situar en el centre de les apreciacions crítiques aquelles obres o aquells autors que fomenten o possibiliten una relació entre totes dues literatures o representen l'hibridisme. Actuar d'aquesta manera —cosa freqüent, en nom del diàleg, en alguns sectors acadèmics i periodístics - implicaria confondre la crítica literària amb la història intel-lectual, $\mathrm{i}$ limitar sociopolíticament les possibilitats dels escriptors en una llengua o en l'altra en obligar-los a ser llegits només en clau política. A més a més, la literatura catalana manté, dins la comunitat interliterària doble, diverses relacions amb la literatura en llengua castellana a Catalunya, obra de ciutadans de definicions nacionals múltiples i posicions diverses en diferents camps, que de vegades excedeixen la Península.

Abans o després de la independència de Catalunya - $\mathrm{i}$ al marge del seu debat explícit - cal identificar i definir la situació de la literatura en castellà a Catalunya, més enllà de les eventuals relacions personals o de les diverses iniciatives institucionals. En l'actualitat és possible apreciar les posicions i relacions següents:

- Literatura en llengua castellana escrita per escriptors catalans que formen part del camp literari definit per la literatura catalana.

- Literatura en llengua castellana escrita per catalans que no participen del camp literari definit per la literatura catalana. Aquesta posició no té 
per què fer-los pertànyer necessàriament a la literatura espanyola, però se'n poden sentir part. Per tant, cal definir molt bé, per a cada cas, quines relacions es mantenen amb el camp literari espanyol —i també, més enllà d'Espanya, amb possibles projeccions envers la literatura americana en llengua castellana. Però caldria definir també quines posicions ocupen, $\mathrm{i}$ com, en el camp literari espanyol i en el context sociocultural català, $\mathrm{i}$ com realitzen les seves propostes polítiques en el camp intellectual, tant a Catalunya com a Espanya.

- Literatura espanyola, en tant que terme privilegiat per les circumstàncies de la comunitat interliterària específica en determinants moments, però no sempre.

- Literatura llatinoamericana, tenint presents dos factors diferents i no necessàriament concomitants: el primer, que el camp editorial català dels anys seixanta i setanta va ser determinant en la constitució actual de la literatura iberoamericana; el segon, que en els darrers anys s'ha produït una reconsideració d'autors americans relativament al marge del procés que aquests autors experimentaven a Espanya, impulsada també per editorials barcelonines, però en una dinàmica completament diferent del pas marcat per l'anomenat boom, ja que els autors actuals no formen un conjunt homogeni, ni cohesionat per una operació editorial d'aquella magnitud, ni sembla que estiguin predisposats a una politització dins el marc espanyol - i en tensió dins el marc català- comparable a la d'alguns autors dels anys seixanta i setanta, com ara Mario Vargas Llosa.

- Literatura escrita per ciutadans catalans d'origen llatinoamericà, residents des de fa dècades — o fins i tot nascuts - a Catalunya, entre d'altres situacions, la qual cosa determina relacions força diferents de les que manté amb la resta de la literatura americana: Roberto Bolaño, Nora Catelli, Edgardo Dobry, Ana Basualdo, Horacio Vázquez Rial, entre molts d'altres. Cal assenyalar que alguns d'aquests autors, de vegades, escriuen també en català: Lolita Bosch, o tenen en la literatura catalana i en la seva situació doble - a Catalunya i a l'Argentina, o a Mèxic- un dels puntals de la seva pròpia trajectòria, com és el cas del poeta Edgardo Dobry amb Gabriel Ferrater. També cal tenir present que alguns d'aquests autors es defineixen a si mateixos només en relació amb la literatura espanyola, però d'altres no es consideren part, de cap manera, d'aquesta literatura, independentment de la qüestió catalana. ${ }^{3}$

- Literatura escrita per llatinoamericans que mantenen una relació especial amb la cultura catalana, per bé que sense residir habitualment a Catalunya: Juan Villoro, Roger Bartra. Cal tenir present que al llarg del segle xx les migracions i els exilis europeus —entre els quals el catalàhan deixat una important empremta en alguns països, especialment a Amèrica del Sud, i que aquesta empremta és també imprescindible per a entendre la cultura catalana. 
A aquestes posicions encara caldria afegir-hi la literatura escrita en català o en castellà, a Catalunya, per persones que tenen com a primera llengua altres llengües europees (Monika Zgustová escriu en txec, en català i en castellà; Simona Skrábec escriu en eslovè i en català) i la literatura escrita en català o en castellà a Catalunya per ciutadans que tenen com a primera llengua alguna de les llengües no europees que sovintegen al nostre país (Najat El Hachmi). I, a més a més, les obres escrites en les seves llengües per escriptors residents a Catalunya, però que no participen directament en el camp literari, ni en una llengua ni en l'altra, sinó que s'hi incorporen tangencialment, per mitjà de les traduccions (per exemple, Caterina Pasqual Söderbaum escriu en suec).

Com a conclusió d'aquest inventari de posicions i possibilitats, que caldria considerar absolutament obert en una situació força canviant com és l'actual, podria afirmar-se que les relacions entre les literatures a Catalunya solen enfocar-se fonamentalment entre la literatura catalana i la literatura en castellà, de manera horitzontal, plana, sense matisos, però aquest petit inventari provisional demostra que aquesta relació conté múltiples variables que cal tenir en compte dins la seva asimètrica reciprocitat; i que a, més a més, es troba emmarcada i condicionada per un conjunt de relacions que constitueixen un veritable context, i no un mer rerefons.

En una Catalunya independent, la situació dels escriptors en castellà haurà canviat profundament, pel que fa a la idea de camp literari i de camp intellectual; i, per descomptat, fins i tot en relació amb el camp polític. També la situació dels escriptors en català haurà canviat; les coses seran molt diferents, $\mathrm{i}$ començarà una nova època per als escriptors en català que restin dins l'Estat espanyol. Tampoc no és d'esperar que romangui inalterada la perspectiva dels escriptors catalans del Rosselló. Però no és concebible que la complexitat de relacions interliteràries a dins de Catalunya no resulti importantíssima en l'articulació actual de la literatura catalana amb la resta de les literatures europees, en una situació que, evidentement, pot originar conflictes, però que converteix el nostre país en un cas límit, sense el qual no pot pensar-se cabalment la identitat literària europea.

Cal construir un marc teòric que permeti pensar la literatura catalana abans i després de la independència de Catalunya, però no des de posicions partidàries o detractores d'aquesta independència, sinó al marge de la sobredeterminació que el debat polític exerceix en les relacions entre literatures a Catalunya. I, per tal de clarificar aquest debat, cal pensar que, si Catalunya algun dia s'independitza d'Espanya, hi continuaran escrivint els mateixos escriptors, en les mateixes llengües, i que els seus lectors, en ambdues llengües, formaran aleshores un camp doble, com a mínim: amb un vessant en català i un altre en castellà que ja no formarà part de manera automàtica del camp literari espanyol, que, de sobte, tindrà una part important del seu llegat canonicohistòric fora del seu territori. Potser caldria començar a pensar que a la península Ibèrica hi ha, si més no, dues literatures diferents en llengua castellana, i que l'espanyola podria no ser la principal, de la mateixa manera que en el context llatinoamericà ja no ho és 
pas. Caldrà repensar també, per raons anàlogues, les situacions en què quedarien els escriptors en català del País Valencià i de les illes Balears, territoris que, pel que sembla, romandrien a dins l'Estat espanyol. De la mateixa manera, alguns dels escriptors espanyols actualment més importants quedarien, a tots els efectes, ubicats fora del territori d'Espanya.

Catalunya sempre ha emprat la idea de frontera com una metàfora que, de sobte, esdevindrà performativa, i caldrà acostumar-se a la seva concreció, evidentment dins el marc d'una Europa futura sense fronteres internes en molts aspectes, però no en tots; el cultural serà, sens dubte, un d'aquests aspectes que, independentment de l'assoliment d'una idea compartida de cultura europea —més enllà de tòpics medievals-, continuarà més vinculat a la diversitat que a la unitat. Avui ja hi ha elements suficients per a pensar que els escriptors catalans que escriuen en castellà no formen exactament part del camp literari espanyol, on el debat tendeix a ubicar-los sense matisos, de vegades a partir d'un inventari tancat d'escriptors amb una posició molt determinada dins el camp, o com si aquests representessin la totalitat dels escriptors que empren el castellà com a llengua literària.

Per tal de començar a pensar totes aquestes qüestions, els processos d'interliterarietat plantejats per Durišin podrien ser matisats pels suggeriments de José Lambert -que al seu torn reprèn la teoria dels polisistemes d'Itamar EvenZohar- ${ }^{4}$ per al qual cal tenir present la no-coincidència entre els mapes literaris, els mapes lingüístics i els mapes polítics, cosa que no fa desaparèixer aquests darrers en nom de la literatura ni exclou els primers d'una politització intrínseca. Per això, sembla d'allò més adient la seva proposta:

I do not claim that political, linguistic, or other principles are unimportant; all I claim is that they are insufficient. It is an assumption widely shared - not only by semioticians but also by economists, sociologists, anthropologists, social psychologists, and even political scientists - that there will always be interchanges, and hence also conflicts, between language, society, religion, etc., entailing a struggle for autonomy or hegemony. This is precisely why the political, religious, or social borderlines are constantly fluctuating. How should literary scientists have better reasons than linguists and others for accepting the nation as basic principle? This is why I would like to suggest that we speak about 'literature in France', 'literature in Germany' or 'literature in Italy', instead of 'German literature', 'French literature', 'Italian literature', and so on. This is a way to indicate that the relationship between literature and socio-political structures is not a self-evident matter but needs to be investigated (Lambert, "In Quest of literary Maps" 72).

És a dir, que si cal imaginar-se una Catalunya independent, cal imaginar-se també la independència per als diversos camps: les seves autonomies $i$ heteronomies, la seva modulació complicada en relació amb el camp literari internacional — que inclouria també la dimensió espanyola, com a internacional, cada cop més clarament, però que mantindria una certa posició d'asimetria dins la internacionalitat per raons lingüístiques, històriques i intellectuals que desborden la idea d'Estat-. D'altra banda, el cas català no deu ser considerat cap ex- 
cepció a Europa pel que fa a la conflictivitat de les relacions entre política i literatura; el que sí que resulta extraordinari, i més interessant, és que, si com assenyala José Lambert "es difícil imaginar cómo una nación determinada podría dar cabida a varios sistemas literarios igualmente completos" (Aproximaciones sistémicas 64), en el cas català no caldria recórrer a la imaginació, sinó a un rigorós treball de constatació, que no faria sinó confirmar l'apreciació de primer cop d'ull: a Catalunya es donen des de fa temps, encara que no sempre hagi estat així, dos sistemes literaris complets. Caldrà tenir molt clar que, en cap societat, ni tothom s'entén en tot, ni tothom ho comparteix tot, i que serà molt difícil però alhora fascinant concebre una capital literària amb dos meridians d'aquesta dimensió.

No es pot esperar al dia de la proclamació de la independència de Catalunya per començar a reflexionar sobre aquestes qüestions - llevat que es vulgui continuar parlant sempre de les mateixes coses, dient sempre el mateix i adreçant-se sempre als mateixos-. Aquest pot ser el gran repte comparatístic al nostre país: des de la fermesa de tenir una de les tradicions culturals més europeistes del nostre entorn, començar a pensar en un nou marc per a la literatura catalana, $i$ les literatures a Catalunya, en la perspectiva de la literatura europea.

ANTONI MARTÍ MONTERDE UNIVERSITAT DE BARCELONA

\section{Notes}

I La polèmica sobre la representació de la cultura catalana a la Fira de Frankfurt l'any 2007 ho demostra clarament.

2 Fernando Cabo Aseguinolaza és, amb Anxo Abuín i César Domínguez l'editor del volum A comparative history of literatures in the Iberian Peninsula. (Amsterdam: Rodopi, 20Io). La seva perspectiva va quedar delimitada en diversos treballs anteriors (Cabo, "El giro espacial de la historiografía literaria") i va ser acompanyada per una important reflexió de diversos comparatistes sobre les Bases metodolóxicas para unha historia comparada das literaturas da península Ibérica, editada per Abuín i Tarrío. Molts dels participants hi incorporaven l'orientació interliterària; Cabo, però, li ha donat una orientació eminentment geoliterària ("National canon formation as interliterary process"). Arturo Casas, especialment en els seus articles publicats a la revista Interlitteraria, de Tartu (Casas, "Sistema interliterario y planificación historiográfica"), va fer les primeres aportacions importants en aplicar els principis de Ďurišin a la situació ibèrica, des d'una perspectiva que incorporava la conflictivitat d'aquest espai com a fet ineludible; en treballs posteriors ("Literaturas nacionais e espacios interculturais"), Casas hi ha apuntat com a renovació el comparatisme actual. Per la seva banda, César Domínguez (2006) va fer la primera síntesi descriptiva de la recepció dels treballs de Ďurišin en l’àmbit ibèric. Galícia, doncs, és el lloc on més clarament ha estat recollit el seu pensament. La primera vegada que es va introduir el terme "interliterari" al nostre context va ser a càrrec de Mario Santana, que tanmateix empra el terme sense posicionar-se respec- 
te al comparatista eslovac ni descriure'l. En darrera instància, ha estat matisat per mi mateix ("La literatura comparada davant les comunitats interliteràries") per al cas ibèric a partir de la idea de "comunitats interliteràries en conflicte", i el vaig introduir també com a possibilitat d'anàlisi en un balanç de la cultura catalana de la primera dècada del segle Xxi ("Grans i petits debats a l'inici del nou millenni”).

3 Pel que fa a aquests autors, un fet de la més gran importància és que, en l'esmentada polèmica sobre la representació de la cultura catalana a la Fira de Frankfurt, les argumentacions que exigien que també hi fossin convidats autors en llengua castellana mai no van proposar el nom de cap d'aquests escriptors, molts dels quals de trajectòria literària desenvolupada a Catalunya força més extensa que alguns dels autors considerats imprescindibles. Això diu molt del primer requisit que calia complir per representar la cultura catalana en castellà: ser absolutament i irreductiblement espanyol i demostrar, amb la pròpia figura i obra, l'espanyolitat de la identitat catalana. Amb aquesta exclusió de la literatura en castellà no espanyola a Catalunya, la polèmica prenia un nítid aire xenòfob absolutament intolerable, però que no va merèixer en el seu moment cap comentari.

${ }_{4} \mathrm{Val}$ a dir que la teoria sistèmica ha estat d'una gran importància per la reflexió sobre la comunitat interliterària específica ibèrica, $\mathrm{i}$ que ha tingut una gran recepció a Galícia (Cabo) i Catalunya (Bou, Poesia i sistema I I-26). Resulta especialment interessant, des del nostre punt de vista, l'anàlisi dels factors i dependències sistèmics (EvenZohar, "Factors i dependències en la cultura"). Tanmateix la represa desenvolupada per Lambert comença una nova etapa d'aquesta aproximació que ja opera de manera molt autònoma respecte al model de l'escola de Tel-Aviv.

\section{REFERÈNCIES}

Abuín, Anxo i Anxo TARrío. Bases metodolóxicas para unha bistoria comparada das literaturas da península Ibérica. Santiago de Compostella: Universidade de Santiago de Compostela, 2004.

Abuín, Anxo i César Domínguez. A Comparative history of literatures in the Iberian Peninsula. Amsterdam: Rodopi, 2010.

Aron, Paul. "Sur le concept d'autonomie". Discours social / Social Discourse 7, 3-4 (1995): 63-72.

BassnetT, Susan. Comparative Literature: A Critical Introduction. Oxford: Blackwell, i 993.

Bonnefoy, Yves, Marc Fumaroli, Herald Weinrich i Michael Zink. Identité littéraire de l'Europe. París: PUF, 2000.

Bou, Enric. Poesia i sistema. La revolució simbolista a Catalunya. Barcelona: Empúries, 1989.

Bourdieu, Pierre. “Existe-t-il une littérature belgue?”. Études de lettres 4 (octubre-desembre 1985): 3-6.

- "Le champ littéraire". Actes de la recherche en sciences sociales 89 (I99I): 3-46.

-. "Les conditions sociales de la circulation international des idées". Actes de la Recherche en Sciences Sociales I45 (2002): 3-8. 
Brunetière, Ferdinand. "La Littérature européenne". Annales Internationales d'Histoire. Congrès de Paris, I900. $6^{e}$ section. Histoire comparée des littératures. París: Armand Colin, I901. 5-38.

Cabo Aseguinolaza, Fernando. "National canon formation as interliterary process: The Spanish case". Literary Research/Recherche littéraire I8.35 (200I): 5 I -62.

-. "El giro espacial de la historiografía literaria". Abuín, Anxo i Anxo TARRÍo. Bases metodolóxicas para unha historia comparada das literaturas da peninsula Ibérica. Santiago de Compostella: Universidade de Santiago de Compostela, 2004. 2 I-43.

Casanova, Pascale. "Nouvelles considérations sur les littératures dites mineures”. Littératures Classiques 3 I (1997): 237-247.

—. La République mondiale des Lettres. París: Seuil, I999.

Casas, Arturo. "Problemas de Historia Comparada: la comunidad interliteraria ibérica". Interlitteraria 5 (2000): 57-75.

- " "Sistema interliterario y planificación historiográfica a propósito del espacio geocultural ibérico". Interlitteraria 8 (2003): 68-96.

- "Catro modelos para una nova historia literaria comparada. Unha aproximación epistemolóxica”. Abuín, Anxo i Anxo TARrío. Bases metodolóxicas para unha historia comparada das literaturas da península Ibérica. Santiago de Compostella: Universidade de Santiago de Compostela, 2004. 45-72.

- "Literaturas nacionais e espacios interculturais. O modelo teórico de $\mathrm{Di}$ onýz Durišin no contexto da renovación da historia literaria comparada". Actas VII Congreso Internacional de Estudos Galegos: mulleres en Galicia: Galicia e os outros pobas da peninsula. Barcelona, 28 ó 3 I de maio de 2003. Coord. H. González i X. Lama. Vol. 2. Ediciós do Castro, Asociación Internacional de Estudios Galegos i Universitat de Barcelona, 2007. 519-530.

Deleuze, Gilles i Félix Guattari. Kafka. Pour une littérature mineure. París: Éditions du Minuit, I975.

Didier, Béatrice, ed. Précis de littérature européene. París: PUF, 2002.

Domínguez, César. "Os horizontes da teoria interliteraria na Peninsula Ibérica: recepción e campo de probas”. A Literatura comparada hoxe. Ed. Anxo Abuín González i César Domínguez. Boletín Galego de Literatura 34, vol. 2. Santiago de Compostella: Universidade de Santiago de Compostela, 2006. 37-65.

Ďurišin, Dionýz. Theory of literary comparatistics. Trad. angl. de Jessie Kocmanová. Bratislava: Slovak Academy of Sciences i Institute of Literary Sciences, I984.

-. Aspects ontologiques du processus interlittéraire. Bratislava: Literárnovedny Ustav, 1985 .

—. Theory of interliterary process. Trad. angl. de Jessie Kocmanová. Bratislava: Veda, 1989.

- Communautés interlittéraires specifiques. Vol. 6: Notions et principes. I Osobitné medziliterárne spolocenstvá. Vol. 6: Pojmy a princípy. Bratislava: 
Academie Slovaque des Sciences, Institut de Littérature Mondiale i Ústav Svetovej Literatúry Sav, 1993.

-. "Le Comunità interletterarie: una categoria fundamentale del processi interliterario". Trad. it. de Pavol Dionýz. Comparare i comparatismi. La comparatistica letteraria oggi in Europa e nel mondo. Ed. Armando Gnisci i Franca Sinopoli. Roma: Lithos, I995. 66-8 I.

ĎurišIn, Dionýz i Armando GnIsci, cur. Il Mediterraneo. Una rete interletterarie. Roma: Bulzoni, 2000.

Even-Zohar, Itamar 1998. "Factors i dependències en la cultura". Traducció d'Anna Romero i Jaume Subirana. Els Marges 62 (I998): 4 I-58.

Espagne, Michel. Les transferts culturels franco-allemands. París: PUF, I999.

Espagne, Michel i Michael Werner. "La Construction d'une référence culturelle allemande en France. Genèse et histoire (1750-1914)". Annales ESC 4 (1987): 969-992.

GÁLIK, Marián. "Comparative literature as a concept of interliterariness and interliterary process". Comparative literature now: Theories and practice. La littérature comparée à l'beure actuelle. Théories et réalisations. Ed. Steven Tötösy de Zepetnek, Milan V. Dimic i Irene Sywenky. París: Honoré Champion, I999.

JURT, Joseph. "Le champ littéraire entre le national et le transnational". L'espace intellectuel en Europe. De la formation des états-nations à la mondialisation XIX ${ }^{e}-X X I^{e}$ siècle. Ed. Gisèle Sapiro. París: La Découverte, 2009. 20I232.

LAMBERT, José. “Aproximaciones sistémicas y literatura en las sociedades multilingües”. Trad. cast. de Montserrat Iglesias Santos. Teoría de los polisistemas. Ed. Montserrat Iglesias Santos. Madrid: Arco Libros, I999. 53-70.

- . "À la recherche de cartes mondiales des littératures". Semper Aliquid Novi. Littérature comparée et littératures d'Afrique. Mélanges offerts à Albert Gérard. Ed. János Riesz i Alain Ricard. Tubingen: Gunter Narr, I990. I09-I 2 I. Trad. ang.: "In Quest of literary World Maps". Functional Approaches to Culture and Translation. (Selected Papers). Amsterdam-Filadèlfia: John Benjamins, 2006. 63-74.

Lemire, Maurice. "L'autonomisation de la 'littérature nationale' au XIX siècle”. Études littéraires 20, I (1987): 75-98.

Martí Monterde, Antoni. "La literatura comparada davant les comunitats interliteràries en conflicte”. ABuín, Anxo i Anxo TARrío. Bases metodolóxicas para unha historia comparada das literaturas da peninsula Ibérica. Santiago de Compostella: Universidade de Santiago de Compostela, 2004. 73-II9.

-. "Grans i petits debats a l'inici del nou millenni". Història, política, societat $i$ cultura als Països Catalans XIII. Dir. Borja de Riquer. Barcelona: Enciclopèdia Catalana, 2008. 298-3 I 2.

Martínez Gil, Víctor. El naixement de l'iberisme catalanista. Barcelona: $\mathrm{Cu}-$ rial, 1997. 
Rodríguez Fischer, Ana. "Juan Marsé y la censura franquista”. Cuadernos Hispanoamericanos $72 \mathrm{I}-722$ (2010): I $2 \mathrm{I}-\mathrm{I} 44$.

SANTANA, Mario. «National literatures and interliterary communities in Spain and Catalonia". Catalan Review I 4.I-2 (2000): I 59-I72.

SzÁvaI, János. "Pour une littérature européenne qui ne se limite pas à celle des 'langues courantes'”. Diditer, Béatrice, ed. Précis de littérature européene. París: PUF, 2002. I 85-190.

Vajdová, Libusa. "Les modes d'organisation des littératures nationales dans les processus interlittéraires". BAuER, Roger et al., ed. Proceedings of the xiith Congress of the International Comparative Literature Association / Actes du XII congrès de l'Association Internationale de Littérature Comparée IV. Munic: Iudicium, I990. 19-27. 